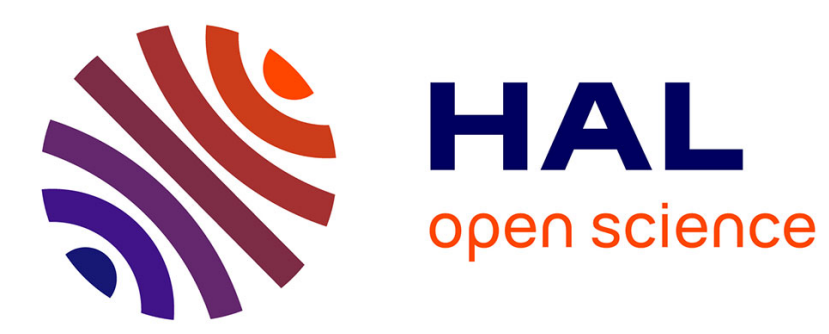

\title{
Tuning reversible supramolecular polymer properties through co-monomer addition
}

Laurent Bouteiller, Benjamin Isare, Guylaine Ducouret, François Lequeux

\section{To cite this version:}

Laurent Bouteiller, Benjamin Isare, Guylaine Ducouret, François Lequeux. Tuning reversible supramolecular polymer properties through co-monomer addition. Supramolecular Chemistry, 2009, 21 (05), pp.416-421. 10.1080/10610270802105106 . hal-00513531

\section{HAL Id: hal-00513531 \\ https://hal.science/hal-00513531}

Submitted on 1 Sep 2010

HAL is a multi-disciplinary open access archive for the deposit and dissemination of scientific research documents, whether they are published or not. The documents may come from teaching and research institutions in France or abroad, or from public or private research centers.
L'archive ouverte pluridisciplinaire HAL, est destinée au dépôt et à la diffusion de documents scientifiques de niveau recherche, publiés ou non, émanant des établissements d'enseignement et de recherche français ou étrangers, des laboratoires publics ou privés. 


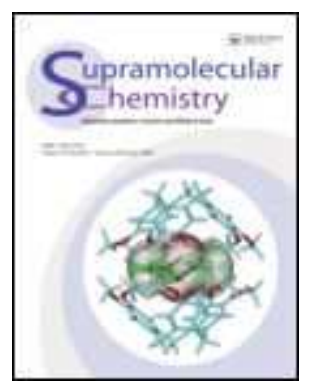

\section{Tuning reversible supramolecular polymer properties through co-monomer addition}

\begin{tabular}{|r|l|}
\hline Journal: & Supramolecular Chemistry \\
\hline Manuscript ID: & GSCH-2008-0008.R2 \\
\hline Manuscript Type: & Full Paper \\
\hline Author: & 03-Apr-2008 \\
\hline Complete List of Authors: & $\begin{array}{l}\text { Bouteiller, Laurent; University Paris 6 } \\
\text { Isare, Benjamin; University Paris 6 } \\
\text { Ducouret, Guylaine; ESPCI } \\
\text { Lequeux, Francois; ESPCI }\end{array}$ \\
\hline Keywords: & supramolecular polymer, organogelator, hydrogen bond, bis-urea \\
\hline & \\
\hline $\begin{array}{l}\text { Note: The following files were submitted by the author for peer review, but cannot be converted } \\
\text { to PDF. You must view these files (e.g. movies) online. }\end{array}$ \\
\hline fig1.cdx
\end{tabular}

\section{scholarONE" \\ Manuscript Central}




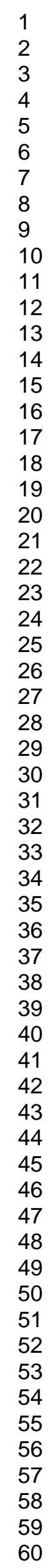

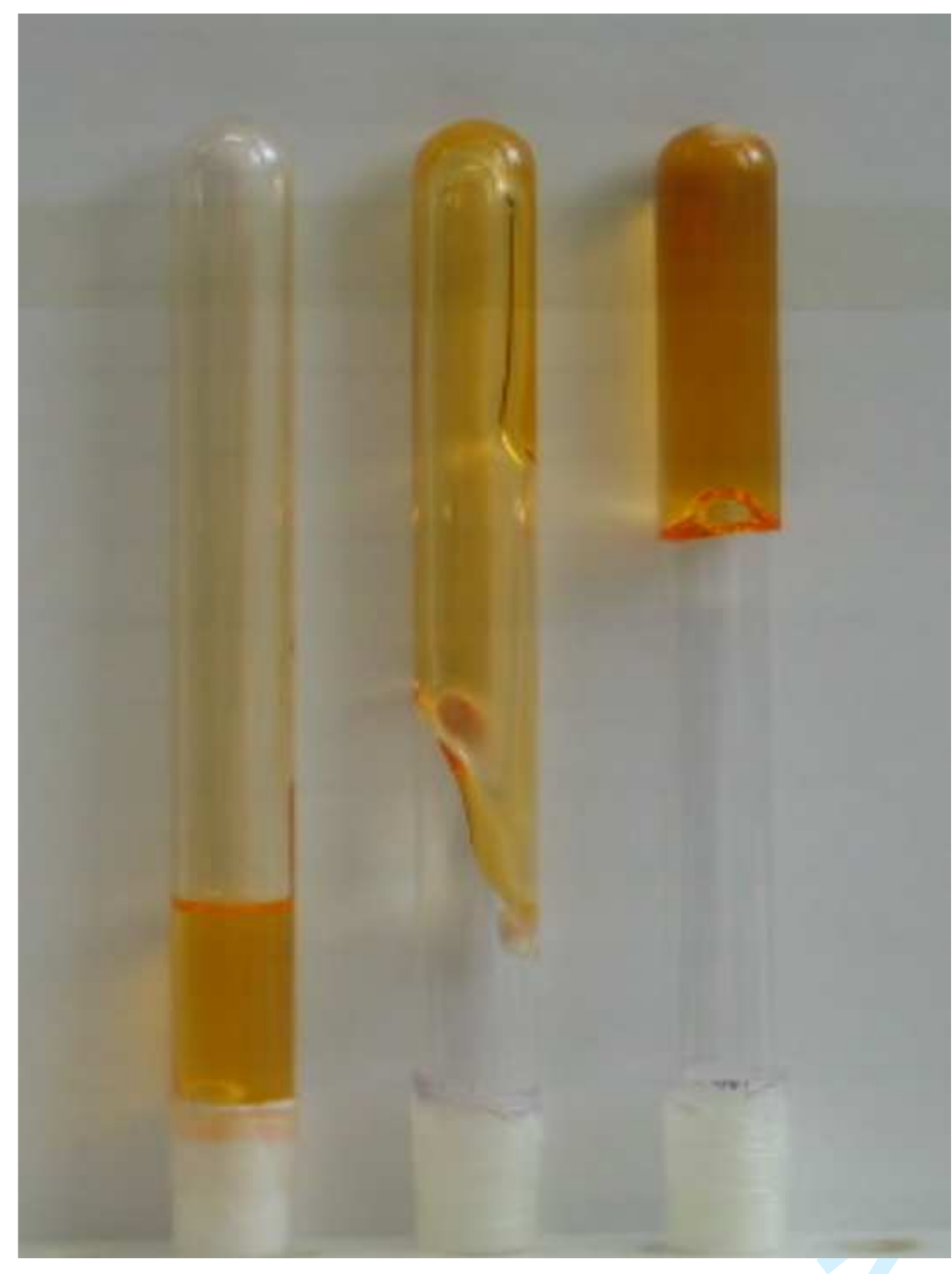

URL: http:/mc.manuscriptcentral.com/tandf/gsch Email: suprachem@mail.cm.utexas.edu 


\title{
Tuning reversible supramolecular polymer properties through co-monomer addition
}

\author{
Benjamin Isare, ${ }^{a}$ Laurent Bouteiller, ${ }^{* a}$ Guylaine Ducouret ${ }^{b}$ and François Lequeux ${ }^{b}$ \\ ${ }^{a}$ Laboratoire de Chimie des Polymères, UMR 7610, CNRS, Université Pierre et Marie Curie, 4 place \\ Jussieu, 75252 Paris Cedex 05, France.E-mail: bouteil@ccr.jussieu.fr \\ ${ }^{b}$ Physico-chimie des Polymères et des Milieux Dispersés, UMR 7615, UPMC-CNRS-ESPCI, 10 rue \\ Vauquelin, 75231 Paris cedex 05, France
}

Unlike most low molar mass organogelators, which form strong gels due to the entanglement of strong molecular aggregates such as crystalline fibres, a few reversible supramolecular polymers form viscoelastic solutions due to the formation of both rigid and dynamic filaments. By using three different bis-ureas which self-assemble according to the same hydrogen bonding pattern and form such rigid reversible supramolecular polymers, we have shown that it is possible to finely tune the properties of the resulting solutions. The critical temperature below which viscoelastic solutions are obtained, and the viscosity of the dilute solutions can be adjusted by changing the co-monomer content. This clearly facilitates gel formulation, which is an important step as far as applications are concerned.

Keywords: supramolecular polymer; organogelator; hydrogen bond; bis-urea.

\section{Introduction}

A large variety of low molar mass compounds are known to form thermoreversible gels at low concentrations in organic solvents. ${ }^{1}$ The overwhelming majority of these organogels are obtained by cooling a hot solution of the organogelator below a critical temperature where molecular aggregation or even crystallization occurs. If the crystals obtained are highly anisotropic, they can form a percolating network, which effectively entraps the solvent. These classical organogels are intrinsically metastable, because close packing of the crystalline fibres, which is a thermodynamically favourable process, leads to a macroscopically biphasic system. However, in some cases this process is kinetically trapped, and the gels obtained are effectively stable for months and can be used in various applications. ${ }^{1}$ In contrast to these materials, a few hydrogen bonded low molar mass compounds have been reported to form thermodynamically stable viscoelastic solutions. ${ }^{2-5}$ Rather than thick crystalline fibres, these reversible polymers ${ }^{6}$ form filaments with a cross-section close to the molecular dimension of the monomer, so that a dynamic exchange between the filaments is possible at room temperature. If the filaments are sufficiently rigid, they can entangle at low concentrations and yield elastic properties at high frequencies. On the other hand, the dynamic nature of the filaments is responsible for viscous flow at low frequencies, because of the reversible breaking of the filaments. The dynamic nature of the filaments is also responsible for the thermodynamic stability, for the self-healing behaviour, and even for the easily tunable properties of the viscoelastic solutions. Indeed, for a thermodynamically stable system, a small incremental change can be expected to lead to a small property variation. This is in contrast to classical organogels, which can be totally disrupted even by a small incremental change, because of their metastable condition. The purpose of this article is to show that tuning the properties of rigid reversible supramolecular polymers by adding co-monomers is indeed a straightforward and efficient methodology. ${ }^{7}$ 


\section{Results and discussion}

\section{Reversible homopolymer structure and properties}

Three bis-urea based monomers (Fig. 1) were considered for this study. The self-assembly of monomer EHUT has been previously characterized by FTIR spectroscopy, small angle neutron scattering (SANS) and rheology. ${ }^{8-10}$ At room temperature, in toluene or dodecane solutions, EHUT forms thick and probably tubular filaments with about three molecules in the cross-section. This supramolecular structure is responsible for the strong viscoelasticity of the solutions (see below). The three monomers considered here (Fig.1) contain the same associating bis-urea unit and thus behave similarly: SANS analyses have shown that all three monomers self-assemble to form thick filaments with the same diameter and the same number of molecules in the cross-section (Table 1). ${ }^{8}$

At high temperatures or at low concentrations, the thick structure disappears in favour of thinner filaments containing a single molecule in the cross-section. ${ }^{8,11}$ The thin filaments do not show viscoelasticity, due to faster dynamics and reduced rigidity of the filaments. The thermal stability of the thick filaments has been tested by FTIR spectroscopy. ${ }^{8}$ The values of the transition temperature above which the thick filaments are unstable $\left(\mathrm{T}^{* *}\right)$ are mentioned in Table 1: the thermal stability of the thick filaments increases in the order BuPEH $<$ EHUT $<$ DMHUT.

The stability of the thick filaments to dilution can be conveniently tested by Isothermal Titration Calorimetry (ITC). ${ }^{12}$ The principle of the technique is to measure the heat evolved while aliquots of a relatively concentrated bis-urea solution are injected into pure solvent (placed in a calorimetric cell, at a fixed temperature). Fig. 2a shows the heat-flow curves obtained when a $0.24 \mathrm{mM}$ bis-urea solution in toluene is incrementally injected into pure toluene at $25{ }^{\circ} \mathrm{C}$, and Fig. $2 \mathrm{~b}$ shows the enthalpograms deduced from the heat-flow curves after integration. The three bis-ureas show qualitatively the same behaviour, but some significant differences are visible. First, the dissociation of the thick filaments is an endothermal process for all three bis-ureas, but Fig. 2a shows that the dissociation of the thick filaments is a slower process for DMHUT than for the other bis-ureas. Second, each enthalpogram (Fig. 2b) displays two thresholds: ${ }^{8}$ the low concentration threshold corresponds to the transition between the thick filaments and the monomers and is not of interest for the present discussion. The second threshold corresponds to the transition between the thick filaments and the thin filaments: its position gives the critical concentration $\left(\mathrm{C}^{* *}\right)$ below which the thick filaments are unstable.\# The values of $\mathrm{C}^{* *}$ are mentioned in Table 1, and they show that the stability toward dilution follows the same trend as the thermal stability: the thick filaments stability increases in the order BuPEH $<$ EHUT $<$ DMHUT.

Simple visual inspection reveals that all three monomers form gels in toluene. Consequently, rheology was used to see if the quantitative differences in the strength of the self-assembly have measurable consequences on the material properties. The experiments were performed in dodecane to avoid artefacts due to solvent evaporation. The stability of the thick filaments is enhanced in dodecane, compared to toluene, but no precise values fot $\mathrm{T}^{* *}$ and $\mathrm{C}^{* *}$ could be obtained. Fig. 3 shows the frequency dependence of the storage and loss moduli for EHUT and DMHUT solutions. ${ }^{\ddagger}$ The results for EHUT (Fig. 3a) prove the viscoelastic nature of the solution. At low frequencies, the mechanical response is dominated by the loss modulus. At higher frequencies the storage modulus is predominant and reaches a plateau value. This signature has previously been interpreted to be due to the entanglement of long and semi-flexible filaments presenting a fast scission and recombination process. ${ }^{5,10}$ DMHUT also shows this characteristic signature, but only at higher temperature (Fig. 3c). Comparison of data at the same temperature and concentration (Fig. $3 \mathrm{a}$ and $3 \mathrm{~b}$ ) shows that the 
characteristic relaxation time (the crossing point of $G^{\prime}$ and $G^{\prime \prime}$ ) for the DMHUT solution is at least two orders of magnitude smaller than in the case of the EHUT solution. This means that the filaments present in the DMHUT solution have slower dynamics. This effect is probably related to the slow dissociation revealed by ITC (Fig. 2a).

\section{Influence of co-monomer composition on transition temperature}

Because of the difference in filament stability between the three monomers, it is of interest to mix them and see if tuning of the properties is possible. Figure 4 shows the evolution of the ratio of FTIR absorbances for EHUT/DMHUT mixtures in toluene. This ratio measures the shape of the vibration band for hydrogen bonded $\mathrm{N}-\mathrm{H}$ groups and is a characteristic of the filament structure: a high value (c.a. 1.25) is attributed to the thick filament structure, whereas a low value (c.a. 1.1) is attributed to the thin filament structure. ${ }^{8}$ Figure 4 shows that the monomer mixtures behave similarly to the pure components, but with a gradual shift of the transition temperature. This means first that copolymers are indeed obtained: if a noninteracting mixture of EHUT and DMHUT filaments were obtained, then two transitions should be detected. A second point worth noting is that the slope of the curves (that is, the cooperativity of the transition) is the same in the case of the copolymers as in the case of the homopolymers. This observation may seem surprising, because based on the monomer structures, statistical copolymers are expected, which means that a broadening of the transition could be expected because of compositional heterogeneity within a copolymer sample. Indeed, in a given mixture, the filaments with a content in EHUT higher than average should present a transition temperature at a lower temperature than the average. However, due to the great length of the filaments, the probability to find a pure EHUT filament in an equimolar EHUT/DMHUT solution is vanishingly small. Consequently, the sharpness of the transition for a mixture means that all the filaments in the sample have a very similar overall composition (the average composition). Compositional fluctuations along the filament most probably occur, but do not affect the slope of the transition because the fluctuations are averaged out over the very long filaments.

Finally, figure 5 shows that, for both monomer mixtures EHUT/DMHUT and EHUT/BuPEH, the transition temperature is close to a linear function of the composition. From a practical point of view, this point is particularly useful because it means that the temperature above which the viscoelastic properties of the solution disappear, can be finely tuned.

\section{Influence of co-monomer composition on dilute solution viscosity}

In order to check if the co-monomer composition also has an influence on properties far from the transition temperature, dilute solution viscosity measurements were performed at $25^{\circ} \mathrm{C}$. Figure 6 shows that the viscosity of the DMHUT solution is much larger than for EHUT: the increased stability of the DMHUT filaments probably means that the DMHUT filaments are longer than the EHUT filaments, explaining the larger viscosity. As a consequence, the viscosity of EHUT/DMHUT mixtures is strongly influenced by composition. The variation is monotonous, but significantly non-linear. In the case of EHUT/BuPEH mixtures, the effect is much less visible: the EHUT solution $\left(\eta / \eta_{0}=4.2\right)$ is only slightly more viscous than the BuPEH solution $\left(\eta / \eta_{0}=4.0\right)$. Consequently, the viscosity of EHUT/BuPEH mixtures is nearly independent of composition. 


\section{Experimental}

The synthesis of bis-ureas was described previously. ${ }^{8}$ Solvents were used as received. Solutions were prepared under stirring or shaking at least 1 week prior to use. Heating at $50^{\circ} \mathrm{C}$ accelerated the dissolution process, but did not affect the measurements.

\section{IR spectroscopy}

Infrared spectra were recorded on a Nicolet Avatar 320 spectrometer in a $\mathrm{KBr}$ cell of $0.1 \mathrm{~cm}$ path length. The temperature was controlled with a heating device (P/N21525) from Specac. Consecutive measurements were separated by at least 10 minutes, to allow for thermal equilibration. Thermal expansion of the solutions was not corrected.

\section{ITC}

Heats of dissociation were measured using a MicroCal VP-ITC titration microcalorimeter. ${ }^{12}$ The sample cell $\left(1.435 \mathrm{~cm}^{3}\right)$ was filled with pure toluene. A relatively concentrated bis-urea solution in toluene was placed in a $0.295 \mathrm{~cm}^{3}$ continuously stirred $(270 \mathrm{rpm})$ syringe. A first $2 \mu \mathrm{L}$ aliquot was injected, without taking into account the observed heat, to remove the effect of solute diffusion across the syringe tip during the equilibration period. Subsequent aliquots of the solution $(5 \mu \mathrm{L})$ were automatically injected into the sample cell every 360 s, until the syringe was empty.

\section{Viscometry}

Measurements were performed with Cannon-Manning semi-micro capillary viscometers. The solutions were not filtered.

\section{Rheology}

Measuring conditions for EHUT were described previously. ${ }^{10}$ Measurements for DMHUT were performed on a strain controlled TA Instrument (ARES-LS1) equipped with a stainless steel Couette cell (diameters: $16.5 \mathrm{~mm}$ - 17mm; height: $13 \mathrm{~mm}$ ). In order to obtain reproducible results, the sample was first heated to $70^{\circ} \mathrm{C}$ for one hour and poured in the Couette geometry regulated at $20^{\circ} \mathrm{C}$ or $35^{\circ} \mathrm{C}$. The measurements were performed after 20 minutes of equilibration. The protocol for each sample was the following: first, the sample was submitted to a strain sweep at $1 \mathrm{~Hz}$ in order to determine the viscoelastic regime, before reaching the non-linear regime the strain sweep was stopped in order to preserve the sample. The strain sweep was followed by a frequency sweep.

\section{Conclusion}

By using three different bis-ureas which self-assemble according to the same hydrogen bonding pattern, we have shown that it is possible to finely tune the properties of the resulting solutions. First, the critical temperature below which viscoelastic solutions are obtained $\left(\mathrm{T}^{* *}\right)$, varies linearly with the co-monomer composition and can thus be rationally adjusted. Second, the viscosity of the dilute solutions can also be finely tuned by changing the comonomer content. This clearly facilitates formulation, which is an important step as far as applications are concerned. Moreover, such a smooth behaviour is difficult to achieve with classical organogelators, which rely on crystalline fibre formation, because it is not a trivial task to find several compounds which can co-crystallize without morphological changes or self-sorting effects. ${ }^{13,14}$ 


\section{Acknowledgements}

C. Rossi and F. Dubut are thanked for their contribution to this project.

\section{Notes and References}

\# In the case of DMHUT, both transitions occur at very similar concentrations. This can be deduced from the value of the enthalpy change on Figure $2 b$, and is unambiguously proved by comparison to the result for the same experiment performed at $35^{\circ} \mathrm{C}$ (Figure $\mathrm{S} 1)$. At this temperature, the 2 transitions are clearly separated.

† Insolubility of BuPEH in dodecane prevented its rheological characterization.

1. Terech, P.; Weiss, R. G. Chem. Rev. 1997, 97, 3133; Terech, P.; Weiss, R. G. Molecular Gels: Materials with self-assembled fibrillar networks; Kluwer: Dordrecht, 2005.

2. Hanabusa, K.; Kawakami, A.; Kimura M.; Shirai, H. Chem. Lett. 1997, 191; Hanabusa, K.; Koto, C.; Kimura, M.; Shirai, H.; Kakehi, A. Chem. Lett. 1997, 429; Shikata, T.; Ogata, D.; Hanabusa, K. Nihon Reoroji Gakkaishi 2003, 31, 229; Sakamoto, A.; Ogata, D.; Shikata T.; Hanabusa, K. Macromolecules 2005, 38, 8983; Ogata, D.; Shikata, T.; Hanabusa, K. J. Phys. Chem. B 2004, 108, 15503; Shikata, T.; Ogata, D.; Hanabusa, K. J. Phys. Chem. B 2004, 108, 508; Sakamoto, A.; Ogata, D.; Shikata, T.; Urukawa O.; Hanabusa, K. Polymer 2006, 47, 956.

3. Brunsveld, L.; Schenning, A. P. H. J.; Broeren, M. A. C.; Janssen, H. M.; Vekemans, J. A. J. M.; Meijer, E. W. Chem. Lett. 2000, 292; van Gorp, J. J.; Vekemans, J. A. J. M.; Meijer, E. W. J. Am. Chem. Soc. 2002, 124, 14759.

4. Boileau, S.; Bouteiller, L.; Lauprêtre, F.; Lortie, F. New J. Chem. 2000, 24, 845; Lortie, F.; Boileau, S.; Bouteiller, L.; Chassenieux, C.; Demé, B.; Ducouret, G.; Jalabert, M.; Lauprêtre, F.; Terech, P. Langmuir 2002, 18, 7218; Simic, V.; Bouteiller, L.; Jalabert, M. J. Am. Chem. Soc. 2003, 125, 13148; Colombani, O.; Bouteiller, L. New J. Chem. 2004, 28, 1373, Obert, E.; Bellot, M.; Bouteiller, L.; Andrioletti, F.; Lehen-Ferrenbach, C.; Boué, F. J. Am. Chem. Soc. 2007, 129, 15601.

5. van der Gucht, J.; Besseling, N. A. M.; Knoben, W.; Bouteiller, L.; Cohen Stuart, M. A. Phys. Rev. E 2003, 67, 051106; Knoben, W.; Besseling, N. A. M.; Bouteiller, L.; Cohen Stuart, M. A. Phys. Chem. Chem. Phys. 2005, 7, 2390; Knoben, W., Besseling, N. A. M.; Cohen Stuart, M. A. Phys. Rev. Lett. 2006, 97, 068301; Knoben, W.; Besseling, N. A. M.; Cohen Stuart, M. A. Langmuir 2007, 23, 6095; Knoben, W.; Besseling, N. A. M.; Cohen Stuart, M. A. J. Chem. Phys. 2007, 126, 024907.

6. Brunsveld, L.; Folmer, B. J. B.; Meijer E. W.; Sijbesma, R. P. Chem. Rev. 2001, 101, 4071; Ciferri, A. Supramolecular Polymers; Marcel Dekker Inc.: New York, 2005; Bouteiller, L. Adv. Polym. Sci. 2007, 207, 79.

7. For examples of reversible copolymers: Takasawa, R.; Murota, K.; Yoshikawa, I.; Araki, K. Macromol. Rapid Commun. 2003, 24, 335; Ligthart, G. B. W. L.; Ohkawa, H.; Sijbesma, R. P.; Meijer, E. W. J. Am. Chem. Soc. 2005, 127, 810.

8. Bouteiller, L.; Colombani, O.; Lortie, F.; Terech, P. J. Am. Chem. Soc. 2005, 127, 8893.

9. $\quad$ Pinault, T.; Isare, B.; Bouteiller, L. Chem. Phys. Chem. 2006, 7, 816.

10. Ducouret, G.; Chassenieux, C.; Martins, S.; Lequeux, F.; Bouteiller, L. J. Coll. Interface Sci. 2007, 310, 624.

11. Vonau, F.; Suhr, D.; Aubel, D.; Bouteiller, L.; Reiter, G.; Simon, L. Phys. Rev. Lett. 2005, 94, 066103; Vonau, F.; Aubel, D.; Bouteiller, L.; Reiter, G.; Simon, L. Phys. Rev. Lett. 2007, 99, 086103.

12. Arnaud, A.; Bouteiller, L. Langmuir 2004, 20, 6858. 
13. For a review on two-component organogelators: Hirst, A. R.; Smith, D. K. Chem. Eur. J. 2005, 11, 5496.

14. Kölbel, M.; Menger, F. M. Langmuir 2001, 17, 4490; Escuder, B.; Marti, S.; Miravet, J. F. Langmuir 2005, 21, 6776; Friggeri, A.; van der Pol, C.; van Bommel, K. J. C.; Heeres, A.; Stuart, M. C. A.; Feringa, B. L.; van Esch, J. Chem. Eur. J. 2005, 11, 5353; Hirst, A. R.; Huang, B.; Castelletto, V.; Hamley, I. W.; Smith, D. K. Chem. Eur. J. 2007, 13, 2180; Zhou, Y.; Xu, M.; Yi, T.; Xiao, S.; Zhou, Z.; Li, F.; Huang, C. Langmuir 2007, 23, 202. 
Table 1 Characteristics of bis-urea self-assembly in toluene

\begin{tabular}{ccccccc}
\hline Bis-urea & $\begin{array}{c}\mathrm{L}^{\mathrm{a}} \\
(\AA)\end{array}$ & $\begin{array}{c}\mathrm{d}^{\mathrm{b}, \mathrm{c}} \\
(\AA)\end{array}$ & $\begin{array}{c}\mathrm{M}_{\mathrm{L}}^{\mathrm{c}, \mathrm{d}} \\
\left(\mathrm{g} \mathrm{mol}^{-1} \AA^{-1}\right)\end{array}$ & $\mathrm{n}^{\mathrm{c}, \mathrm{e}}$ & $\begin{array}{c}\mathrm{T}^{* * \mathrm{f}} \\
\left({ }^{\circ} \mathrm{C}\right)\end{array}$ & $\begin{array}{c}\mathrm{C}^{* * \mathrm{~g}} \\
\left(\mathrm{~mol} \mathrm{~L}^{-1}\right)\end{array}$ \\
\hline DMHUT & 25 & 25 & 790 & 2.5 & 63 & $1.810^{-5}$ \\
EHUT & 25 & 26 & 800 & 2.5 & 43 & $2.910^{-5}$ \\
BuPEH & 27.5 & 30 & 910 & 2.3 & 35 & $3.710^{-5}$ \\
\hline
\end{tabular}

${ }^{a}$ Largest dimension of the fully extended monomer. ${ }^{b}$ Diameter of the filament cross-section. ${ }^{c}$ Derived from SANS measurement ${ }^{8}$ of a $22 \mathrm{mM}$ solution in $\mathrm{d}_{8}$-toluene, at $22^{\circ} \mathrm{C}$. ${ }^{d}$ Mass per unit length of the filament. ${ }^{e}$ Number of bis-urea molecules in the cross-section, assuming a repeat distance of $4.6 \AA^{f}{ }^{f}$ Transition temperature between thick and thin filament structure, determined by FTIR measurement ${ }^{8}$ of a $12.5 \mathrm{mM}$ solution in toluene. ${ }^{g}$ Concentration corresponding to the transition between thick and thin filament structure at $25^{\circ} \mathrm{C}$, determined by ITC (see Fig. $2 \mathrm{~b}$ ). 
Figure captions

Figure 1. Structure of studied bis-ureas

Figure 2. Heat effect produced by injecting a $0.24 \mathrm{mM}$ toluene solution of bis-urea into toluene at $25^{\circ} \mathrm{C}(5-\mu \mathrm{L}$ aliquots). Heat flow produced by the first two injections (a). Enthalpogram for the whole experiment (b).

Figure 3. Storage $\mathrm{G}^{\prime}(\bullet)$ and loss $\mathrm{G}^{\prime \prime}(\square)$ modulus versus frequency for bis-urea solutions in dodecane, at a concentration of $1 \mathrm{~g} / \mathrm{L}(2.3 \mathrm{mM})$. (a) EHUT, $20^{\circ} \mathrm{C}$; (b) DMHUT, $20^{\circ} \mathrm{C}$; (c) DMHUT, $35^{\circ} \mathrm{C}$.

Figure 4. Ratio of absorbances at 3328 and $3300 \mathrm{~cm}^{-1}$ for $12.5 \mathrm{mM}$ toluene solutions of EHUT/DMHUT mixtures (100/0: •; 75/25: $\diamond ; 50 / 50: \bullet ; 25 / 75: \square ; 0 / 100: \Delta)$ versus temperature. Both heating and cooling runs are represented, showing the absence of hysteresis.

Figure 5. Transition temperature between thick and thin filaments, for $12.5 \mathrm{mM}$ EHUT/DMHUT $(\bullet)$ and EHUT/BuPEH $(\diamond)$ solutions in toluene, versus EHUT molar content.

Figure 6. Relative viscosity $\left(\eta / \eta_{0}\right)$, for $0.8 \mathrm{mM}$ EHUT/DMHUT $(\bullet)$ and EHUT/BuPEH $(\diamond)$ solutions in toluene, versus EHUT molar content $\left(25^{\circ} \mathrm{C}\right)$.

Figure S1. Enthalpogram produced by injecting a $0.24 \mathrm{mM}$ toluene solution of DMHUT into toluene at 25 or 35 ${ }^{\circ} \mathrm{C}\left(5-\mu \mathrm{L}\right.$ aliquots). At $35^{\circ} \mathrm{C}$, two transitions $\left(\mathrm{C}^{*}\right.$ and $\left.\mathrm{C}^{* *}\right)$ are visible; at $25^{\circ} \mathrm{C}$, the two transitions coincide. 
Figure 2. Heat effect produced by injecting a $0.24 \mathrm{mM}$ toluene solution of bis-urea into toluene at 25 ${ }^{\circ} \mathrm{C}(5-\mu \mathrm{L}$ aliquots). Heat flow produced by the first two injections (a). Enthalpogram for the whole experiment (b).

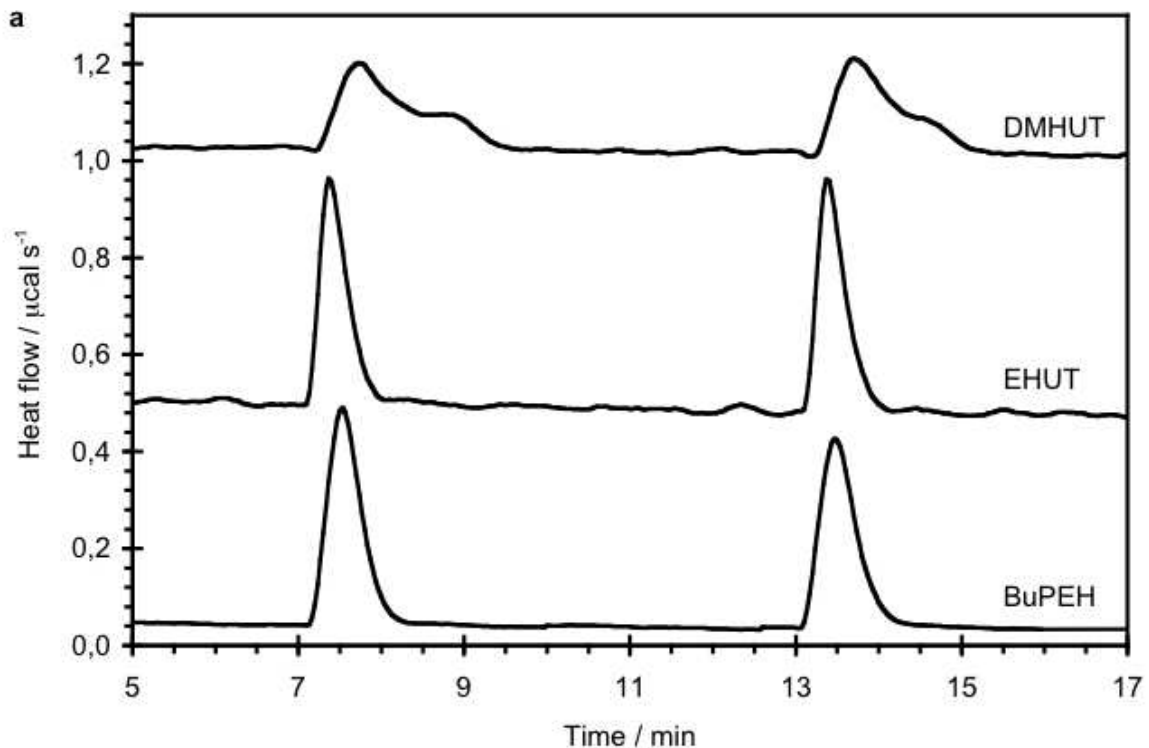




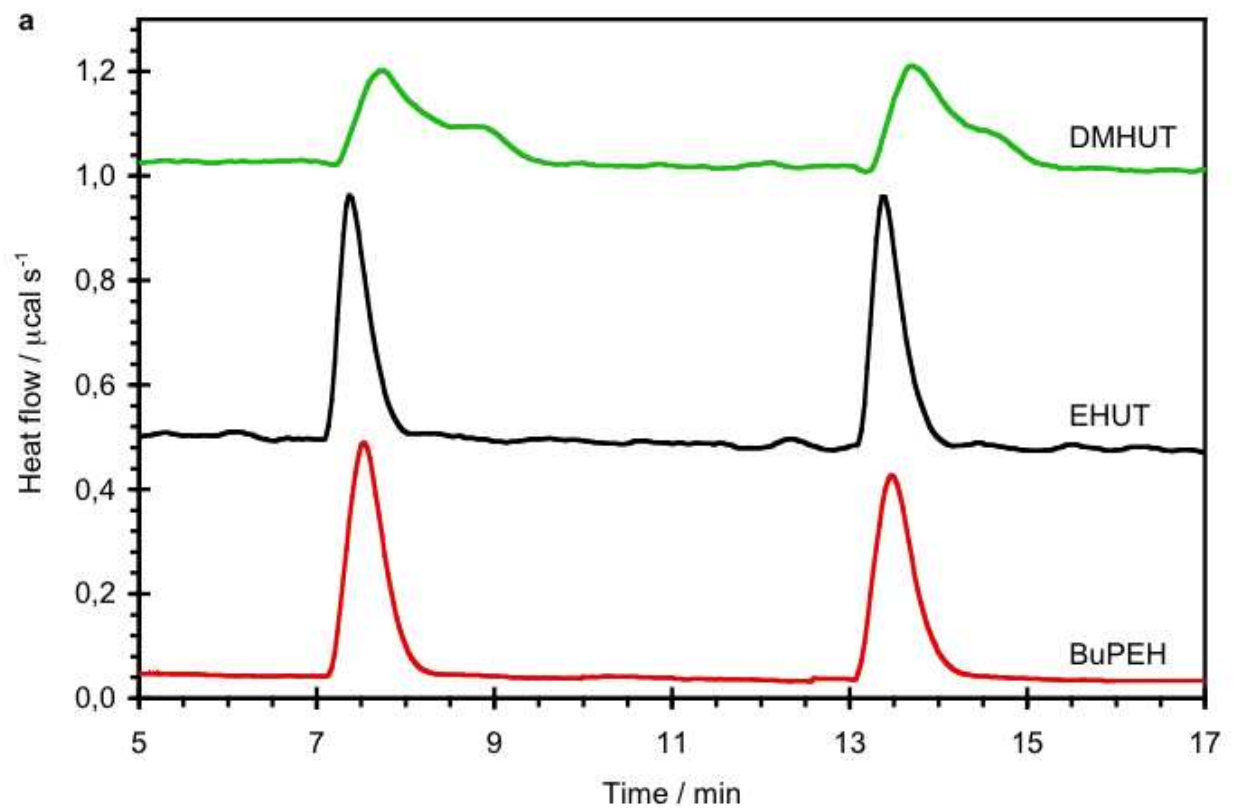

Figure 2. Heat effect produced by injecting a $0.24 \mathrm{mM}$ toluene solution of bis-urea into toluene at 25 ${ }^{\circ} \mathrm{C}$ (5- $\mu \mathrm{L}$ aliquots). Heat flow produced by the first two injections (a). Enthalpogram for the whole experiment (b). 
b

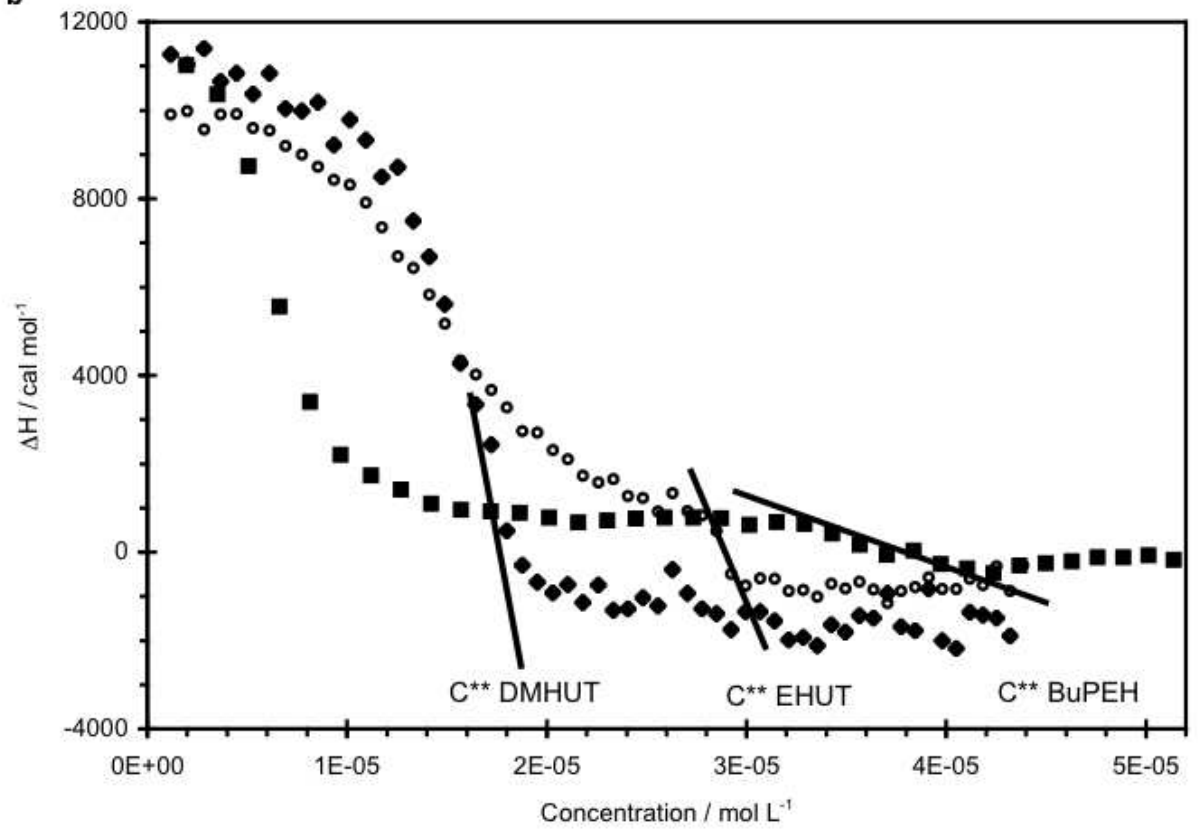

Figure 2. Heat effect produced by injecting a $0.24 \mathrm{mM}$ toluene solution of bis-urea into toluene at 25 ${ }^{\circ} \mathrm{C}(5-\mu \mathrm{L}$ aliquots). Heat flow produced by the first two injections (a). Enthalpogram for the whole experiment (b). 
b

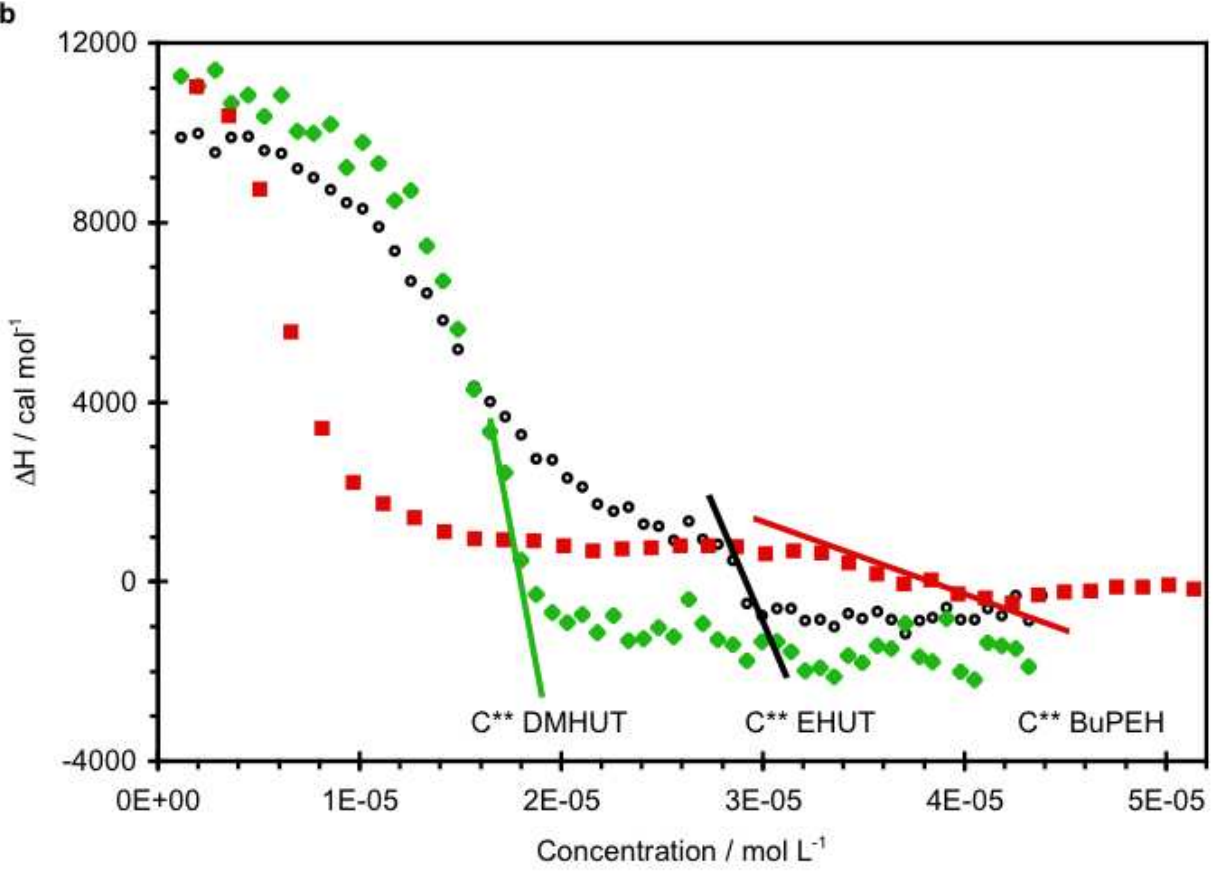

Figure 2. Heat effect produced by injecting a $0.24 \mathrm{mM}$ toluene solution of bis-urea into toluene at 25 ${ }^{\circ} \mathrm{C}$ (5- $\mu \mathrm{L}$ aliquots). Heat flow produced by the first two injections (a). Enthalpogram for the whole experiment (b). 
a

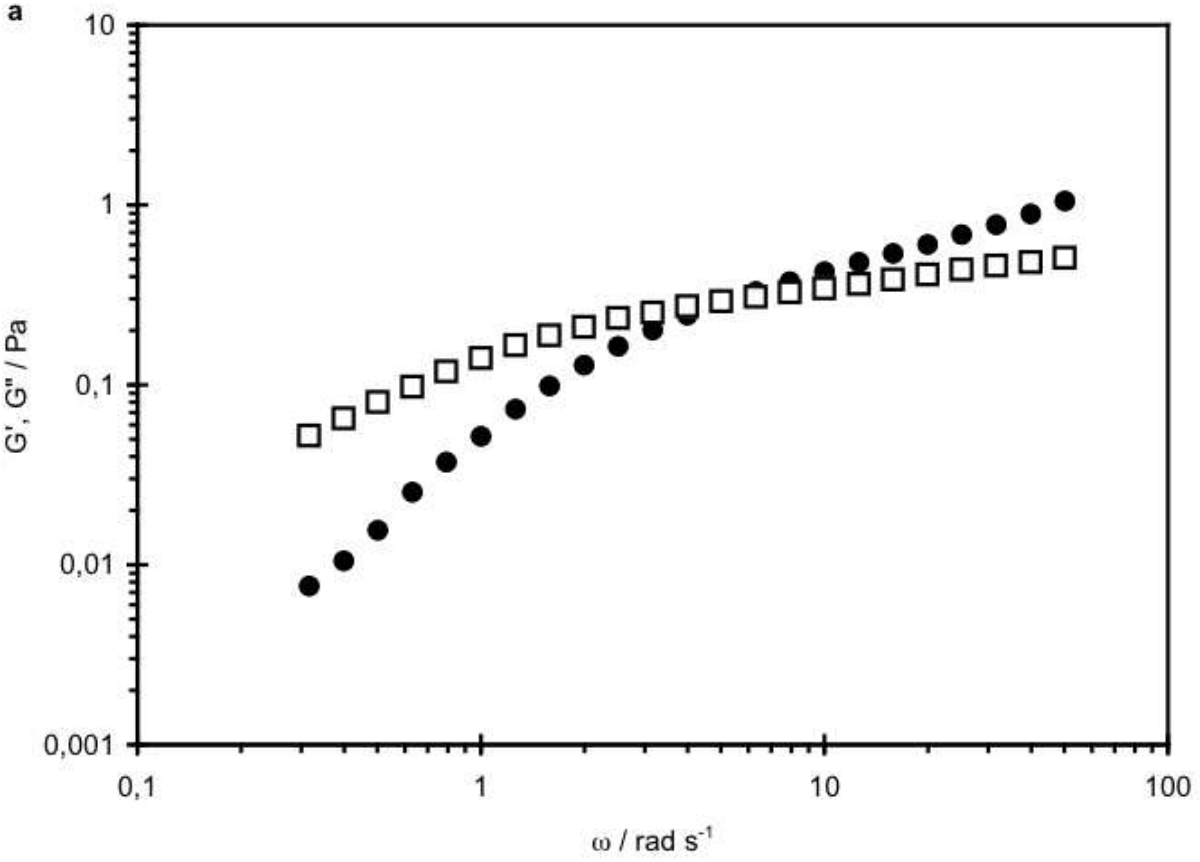

Figure 3. Storage $\mathrm{G}^{\prime}(\bullet)$ and loss $\mathrm{G}^{\prime \prime}(*)$ modulus versus frequency for bis-urea solutions in dodecane, at a concentration of $1 \mathrm{~g} / \mathrm{L}(2.3 \mathrm{mM})$. (a) EHUT, $20^{\circ} \mathrm{C}$; (b) DMHUT, $20^{\circ} \mathrm{C}$; (c) DMHUT, $35^{\circ} \mathrm{C}$. 
1

2

3

4

5

6

7

8

9

10

11

12

13

14

15

16

17

18

19

20

21

22

23

24

25

26

27

28

29

30

31

32

33

34

35

36

37

38

39

40

41

42

43

44

45

46

47

48

49

50

51

52

53

54

55

56

57

58

59

60

b

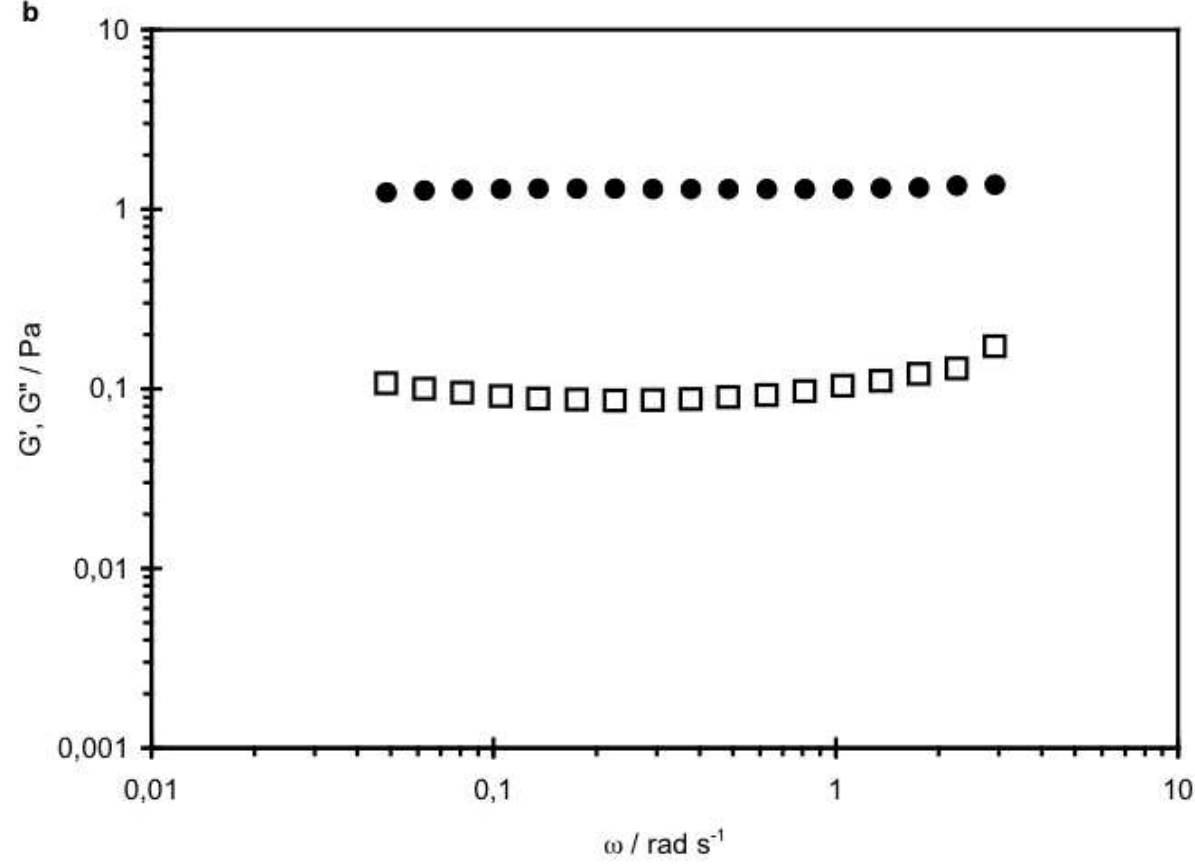

Figure 3. Storage G' (Ẫ ) and loss G" $(*)$ modulus versus frequency for bis-urea solutions in dodecane, at a concentration of $1 \mathrm{~g} / \mathrm{L}(2.3 \mathrm{mM})$. (a) EHUT, $20^{\circ} \mathrm{C}$; (b) DMHUT, $20^{\circ} \mathrm{C}$; (c) DMHUT, $35^{\circ} \mathrm{C}$.

URL: http:/mc.manuscriptcentral.com/tandf/gsch Email: suprachem@mail.cm.utexas.edu 


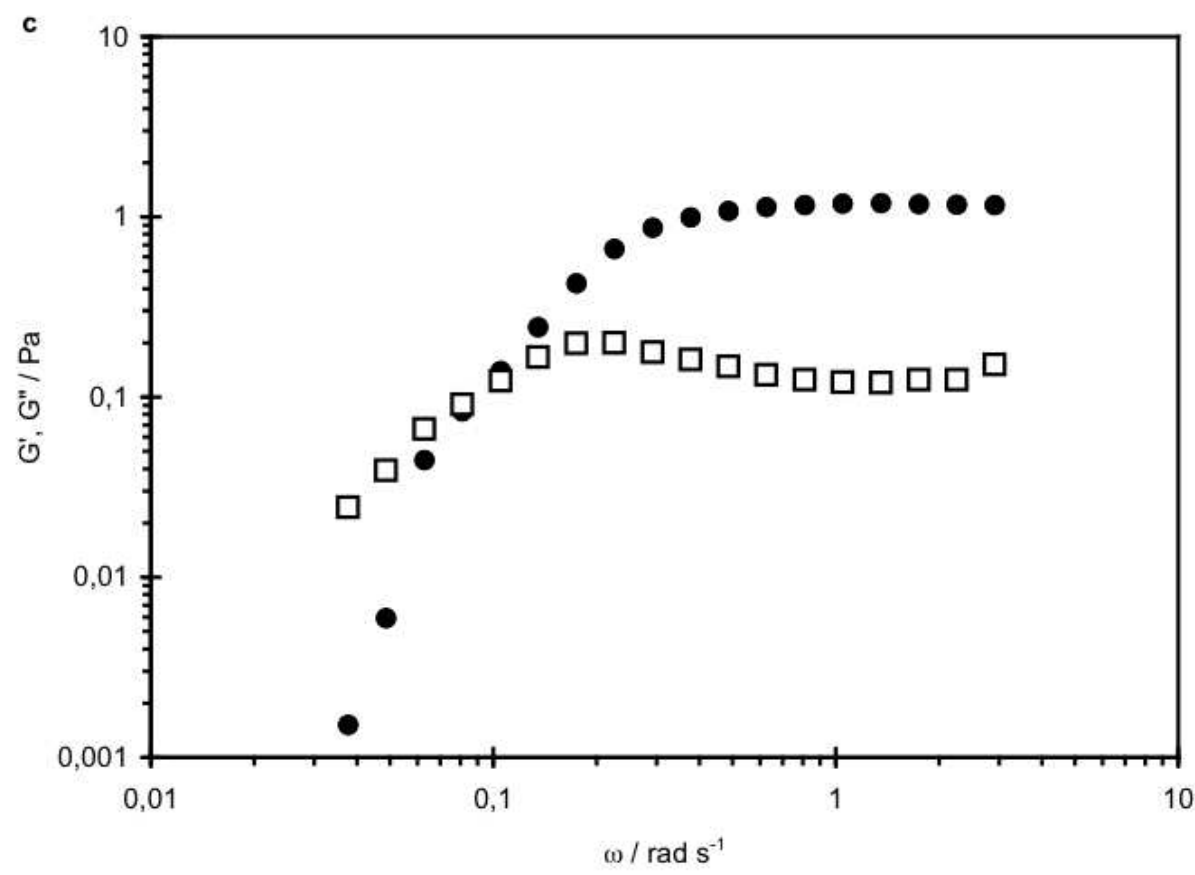

Figure 3. Storage G' (Ẫ ) and loss G" $(*)$ modulus versus frequency for bis-urea solutions in dodecane, at a concentration of $1 \mathrm{~g} / \mathrm{L}(2.3 \mathrm{mM})$. (a) EHUT, $20^{\circ} \mathrm{C}$; (b) DMHUT, $20^{\circ} \mathrm{C}$; (c) DMHUT, $35^{\circ} \mathrm{C}$. 


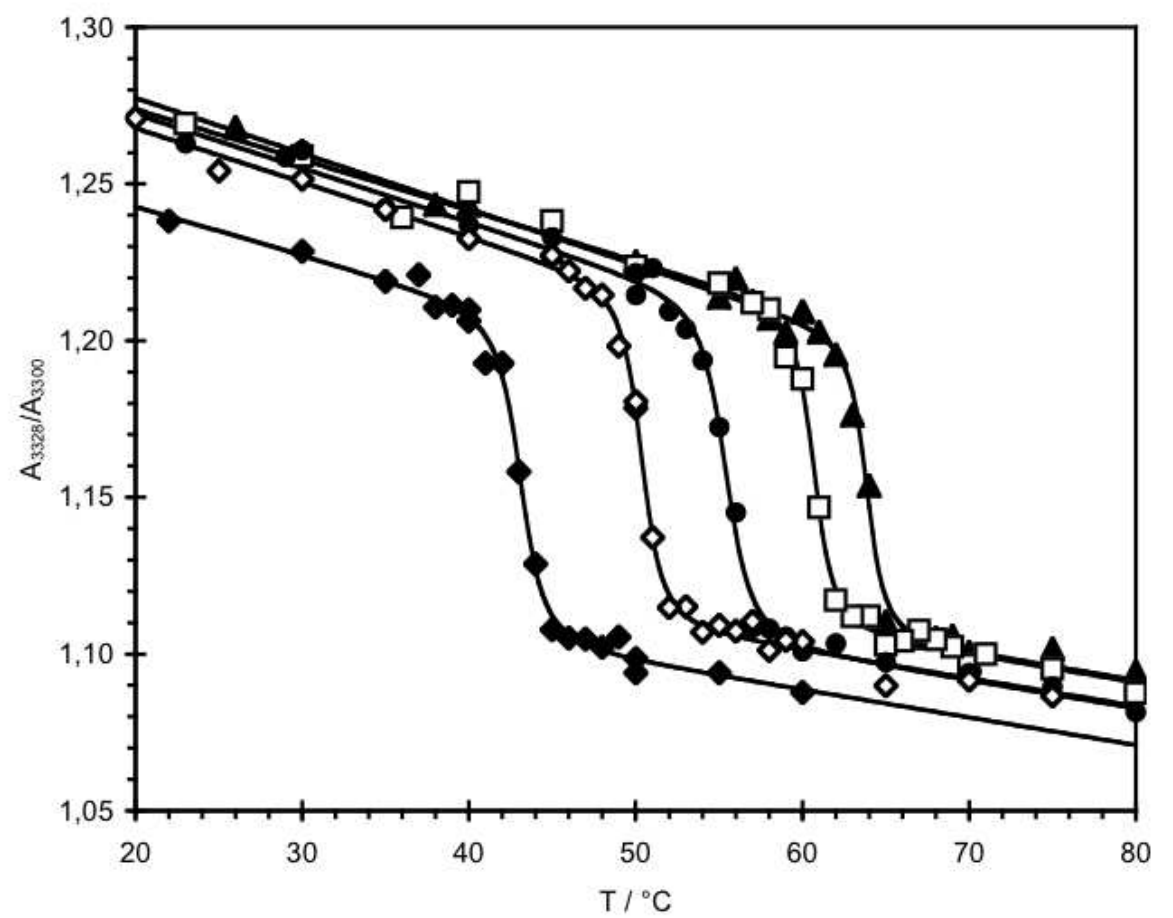

Figure 4. Ratio of absorbances at 3328 and $3300 \mathrm{~cm}-1$ for $12.5 \mathrm{mM}$ toluene solutions of EHUT/DMHUT mixtures (100/0: ; 75/25: $\varnothing ; 50 / 50: \bullet ; 25 / 75: * ; 0 / 100: \AA)$ versus temperature. Both heating and cooling runs are represented, showing the absence of hysteresis. 
Figure 5. Transition temperature between thick and thin filaments, for $12.5 \mathrm{mM}$ EHUT/DMHUT $(\bullet)$ and EHUT/BuPEH $(\varnothing)$ solutions in toluene, versus EHUT molar content. 
1

2

3

4

5

6

7

8

9

10

11

12

13

14

15

16

17

18

19

20

21

22

23

24

25

26

27

28

29

30

31

32

33

34

35

36

37

38

39

40

41

42

43

44

45

46

47

48

49

50

51

52

53

54

55

56

57

58

59

60

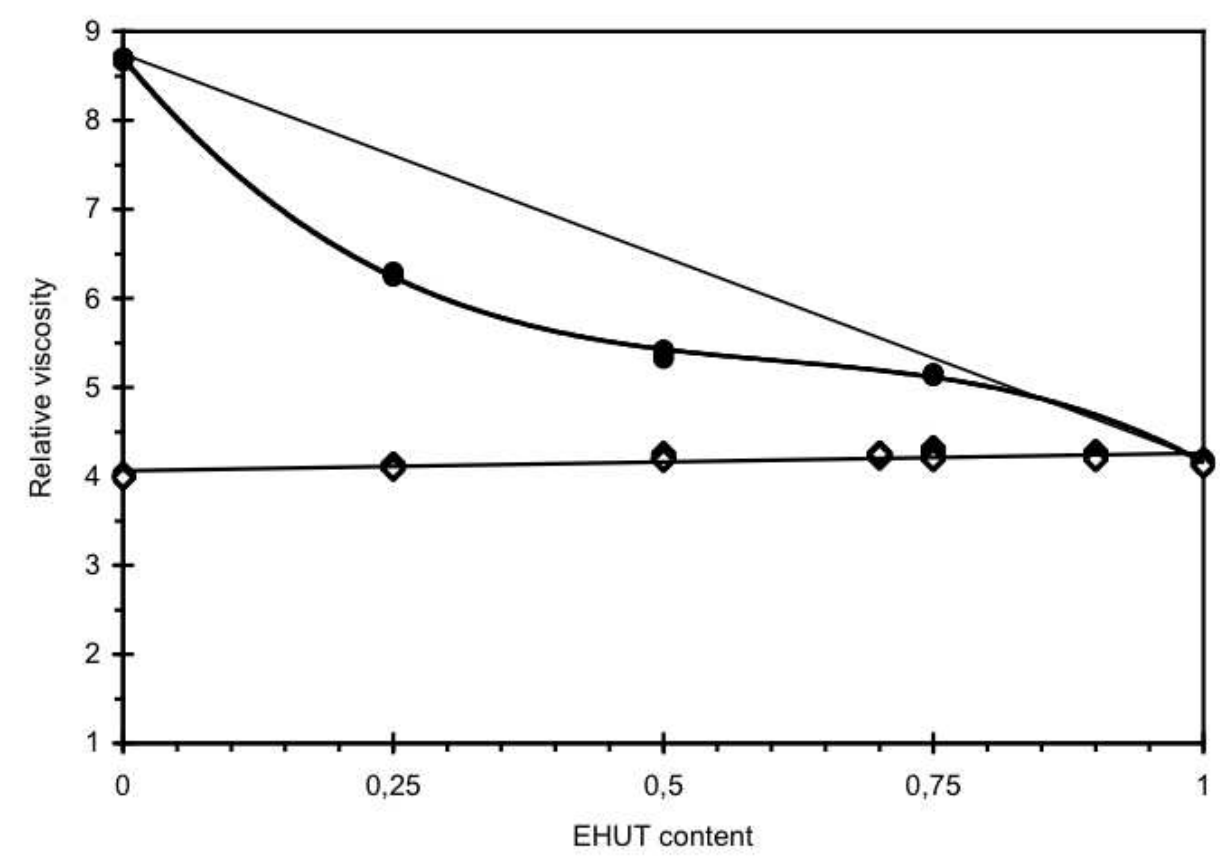

Figure 6. Relative viscosity $(\eta / \eta 0)$, for $0.8 \mathrm{mM}$ EHUT/DMHUT $(\bullet)$ and EHUT/BuPEH $(\varnothing)$ solutions in toluene, versus EHUT molar content $\left(25^{\circ} \mathrm{C}\right)$. 


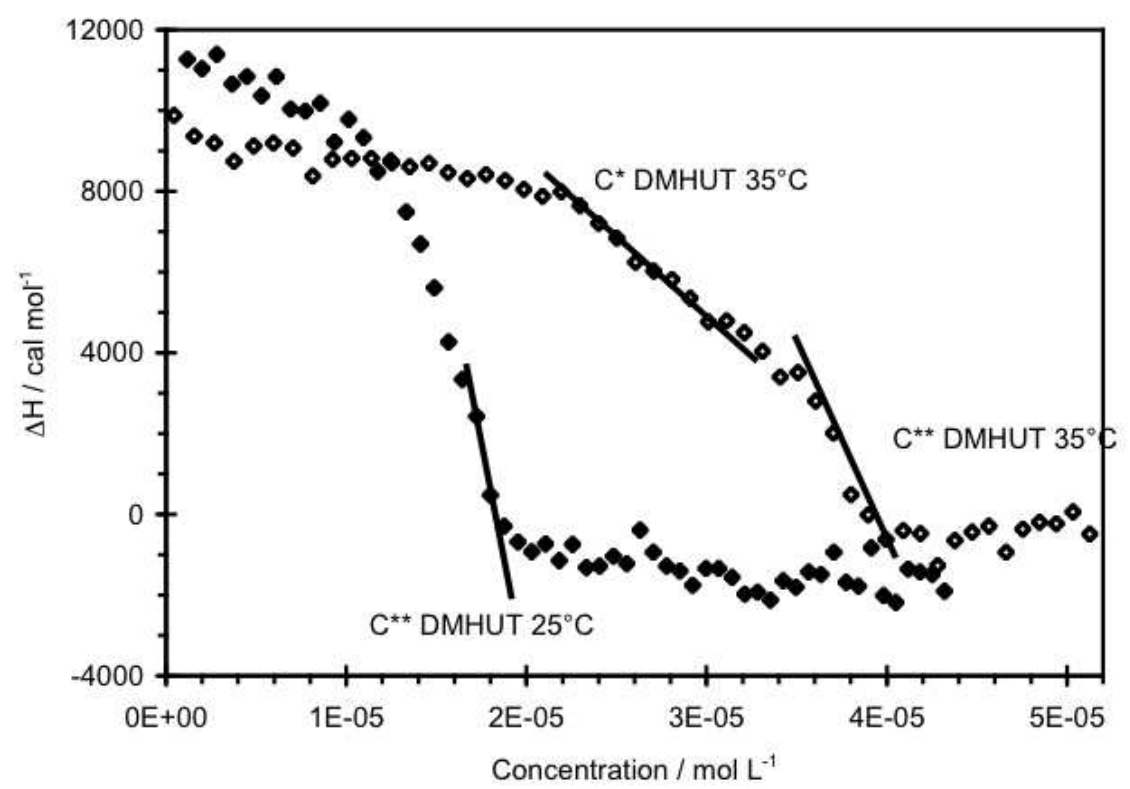

30

Figure S1. Enthalpogram produced by injecting a $0.24 \mathrm{mM}$ toluene solution of DMHUT into toluene at 25 or $35^{\circ} \mathrm{C}\left(5-\mu \mathrm{L}\right.$ aliquots). At $35^{\circ} \mathrm{C}$, two transitions ( $\mathrm{C}^{*}$ and $\mathrm{C}^{* *}$ ) are visible; at $25^{\circ} \mathrm{C}$, the two transitions coincide. 
Figure S1. Enthalpogram produced by injecting a $0.24 \mathrm{mM}$ toluene solution of DMHUT into toluene at 25 or $35^{\circ} \mathrm{C}\left(5-\mu \mathrm{L}\right.$ aliquots). At $35^{\circ} \mathrm{C}$, two transitions (C* and $\mathrm{C}^{* *}$ ) are visible; at $25^{\circ} \mathrm{C}$, the two transitions coincide. 